\title{
Effects of finite rifting times on the development of sedimentary basins
}

\author{
James R. Cochran \\ Lamont - Doherty Geological Observatory of Columbia University, Palisades, NY 10964 (U.S.A.)
}

Received June 27, 1983

Revised version received September 13, 1983

\begin{abstract}
Most thermo-mechanical models for the development of sedimentary basins have assumed that the rifting responsible for the formation of the basin occurred instantaneously and have examined the post-rift development of the basin. This assumption greatly simplifies the mathematical treatment, but is not in accord with what is found in nature, where 10to 50-m.y. rifting events commonly accompany the formation of sedimentary basins and continental margins. The effects of a finite rifting time on the development of sedimentary basins are examined using an analytic technique which allows an arbitrary rifting history in both time and space and which considers the effects of both vertical and horizontal heat transfer. This technique allows the thermal structure of the lithosphere to be calculated throughout the rifting event and thus permits the subsidence history and surface heat flow of the developing basin to be traced.

The effect of a finite-duration extension event is that heat is lost during rifting increasing the syn-rift subsidence at the expense of the post-rift. Lateral heat flow, which was not included in previous studies of the effect of finite rifting times, has a significant effect on the subsidence history, distribution of sediments and thermal history. In particular, the post-rift subsidence is decreased by more than $25 \%$ for a $20-\mathrm{m}$.y. rifting event and by more than 10-15\% for a rifting event as short as $10 \mathrm{~m} . \mathrm{y}$. This will significantly decrease the subsidence rates in the post-rift stage and implies that inferences concerning the structure, development and thermal history of the basin derived from using " $\beta$-curves" to interpret backstripped subsidence can be greatly in error.

Variations in syn-rift sediment accumulation and lithospheric thermal structure at the end of rifting resulting from different rifting histories can interact with other factors, such as the flexural response of the lithosphere to sediment loading, to affect the final width of the basin, the total amount of sediments that accumulate and the basin stratigraphy.
\end{abstract}

\section{Introduction}

There is general agreement that the basic mechanism responsible for the tectonic subsidence of continental margins and of many sedimentary basins is thermal contraction following heating of the lithosphere. This conclusion results from the observation that the subsidence tends to decrease exponentially with time in a manner similar to a mid-ocean ridge and apparently with a similar time constant [1]. Although heating of the lithosphere accompanies basin development, it cannot,

Lamont-Doherty Geological Observatory Contribution No. 3518. of itself, cause the basin to form since if the lithosphere is simply heated, it will expand creating a swell which will then subside back to the original elevation. This process will not result in the formation of a basin in which sediments can collect. Thus an additional process must accompany the heating which causes the lithosphere to subside below the original base level providing space for sediments.

A great advance in understanding the formation of sedimentary basins resulted from the realization that the process responsible for the creation of many sedimentary basins is horizontal extension of the crust and lithosphere. McKenzie [2] developed a simple but elegant model in which 
STRETCHING MODEL (McKenzie, 1978)

A
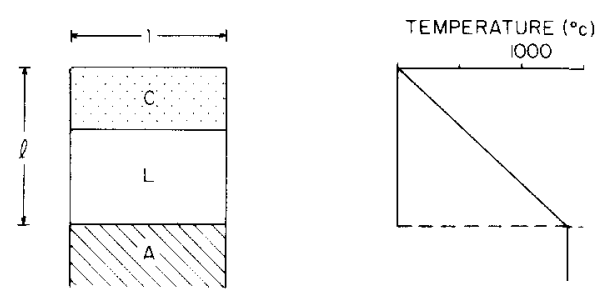

$B+=0$
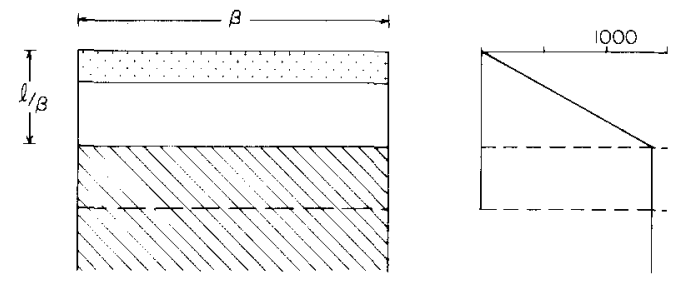

$\mathrm{C} \nmid \rightarrow \infty$
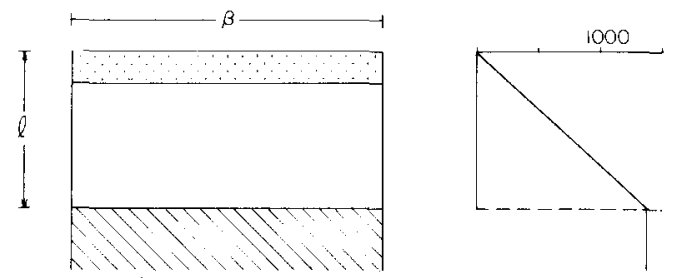

Fig. 1. Simple model for crustal extension. Unit length of lithosphere (A) is at time $T=0$ instantaneously extended to length $\beta(B)$, thinning crust and lithosphere to $1 / \beta$ of their original thickness resulting in a higher temperature gradient. With time, the lithosphere thickens and the thermal gradient returns to its original state (C). Knowledge of initial and final temperature distributions allows surface elevation and heat flow to be calculated as a function of time.

extension is responsible for both the heating of the lithosphere and the crustal thinning necessary to produce a sedimentary basin. The extension model assumes a lithosphere of thickness $l$ with a crust of thickness $t_{\mathrm{c}}$ over an isothermal asthenosphere. A simple linear temperature gradient is assumed in the lithosphere (Fig. 1A). At some time $t=0$, a unit length of lithosphere is assumed to be instantaneously extended to a length $\beta$ in an unspecified manner. As a result, the lithospheric thickness is decreased to $l / \beta$ and the crustal thickness to $t_{c} / \beta$, while the asthenosphere passively rises in response to the lithospheric thinning causing a steepened temperature gradient (Fig. 1B).

The first result of the extension is an isostatic adjustment referred to as the "fault bounded" or "initial" subsidence and which is due to the fact that the extension changes the mass in a vertical column. This is followed by the thermal subsidence as the lithosphere cools and thickens to its pre-extension equilibrium thickness (Fig. 1C). Since the initial and final thermal states are known, the temperature distribution and surface heat flow can be determined as a function of time. Knowledge of the thermal structure and thus of the densities allows the subsidence history of the extended region to be calculated [2].

Application of the McKenzie [2] extension model to geological data is, however, not completely straightforward. The subsidence history recorded by the sediments preserved in a sedimentary basin reflects the interaction of a number of processes. The thermal "tectonic" subsidence is modified by the response of the lithosphere to the load represented by the sediments, by compaction and lithification of the sediments, and by environmental factors such as the sediment supply budget and sea level changes. As a result models have become more complicated as factors such as lateral heat conduction [3,4], lithospheric flexure [5,6] and the possibility of lithospheric thinning in addition to that related to crustal extension [7] were included.

One feature of the original model [2] that has been retained by all of the variations is the assumption that the extension has occurred instantaneously. This is an extremely attractive assumption because it creates a simple, well defined initial condition for the thermal calculations which greatly simplifies the analysis of the post-rift behavior of the basin. The assumption of instantaneous extension has also appeared to be verified by calculations carried out by Jarvis and McKenzie [8]. They considered a two-dimensional model in which crust and lithosphere are stretched horizontally in a pure shear strain field with asthenospheric material flowing upwards to replace the outflowing lithosphere and obtained a solution for the temperature structure of the lithosphere (and thus for the eleva- 
tion and heat flow) in terms of a sum of numerically evaluated eigenfunctions. The conclusion drawn by Jarvis and McKenzie [8] from their modeling is that "For most basins the simple model gives reasonably accurate results provided the duration of stretching is less than $20 \mathrm{Ma}$ " $[8, \mathrm{p}$. 42].

There are, however, at least two reasons why the effects of a finite-length rifting event need to be systematically evaluated. First, the calculations carried out by Jarvis and McKenzie [8] only considered vertical heat conduction. Steckler $[3,9]$ has shown that lateral conduction of heat across the horizontal temperature gradient set up by the lithospheric thinning significantly affects the subsidence rates and the stratigraphy both within the basin and on its margins for the instantaneous model. Specifically, the subsidence rate is increased in the early stage of the basin's history as heat is conducted laterally out into the cooler surrounding areas where it causes uplift which can amount to several hundred meters $[3,9]$.

Similar large horizontal temperature gradients exist during the syn-rift development of a basin and it thus might be expected that lateral effects will also be significant in the syn-rift development. Neglect of lateral heat conduction will cause the approach used by Jarvis and McKenzie [8] to underestimate the heat lost from the rifted region during the rift process. The magnitude of this effect, the length of rifting event for which it becomes significant, and the consequences for the development of the basin need to be systematically evaluated.

The second reason for considering the effects of a finite-length rifting event is that there is increasing evidence that the rifting stage in the development of a basin or a margin quite often lasts for 20-50 m.y., significantly longer than the 20-m.y. period which has been considered [8] to be the rifting time for which the instantaneous model can be applied. For example, Jansa et al. $[10,11]$ have identified Carnian-Norian (212-200 m.y. B.P.) red beds and evaporites in wells along the Atlantic margin of Canada, where sedimentological [12] and magnetic [13] data imply seafloor spreading began in the Bajocian (about 170 m.y. B.P.). A modern example of extended rifting is the Red Sea

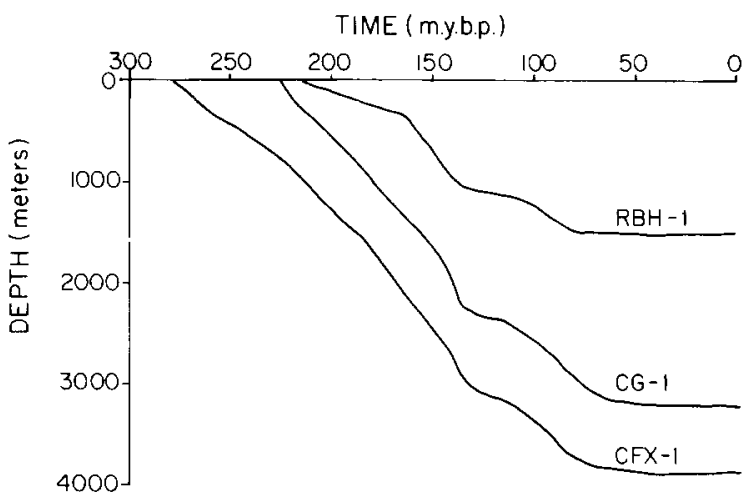

Fig. 2. Subsidence curves determined from three wells in the Paris Basin [13]. Note that well CFX-1 within the rift basin began to subside about $60 \mathrm{~m}$.y. prior to wells CG-1 and RBH-1 which are outside of the rift in the flexurally controlled portion of the basin and thus only show post-rift subsidence. CG-1 is very near the rift basin and RBH-1 is well away from it.

where rifting began $20-26$ m.y. B.P. near the Oligocene-Miocene boundary [14] while organized seafloor spreading began in the southern Red Sea only 4-5 m.y. B.P. [15]. There is no recognizable spreading axis in the northern Red Sea and that region appears to still be in the rifting stage, with extension occurring diffusely over an area perhaps $100 \mathrm{~km}$ wide [16].

Extended rifting events also accompany the development of intracratonic basins. For example, subsidence in the Paris Basin appears to have begun about 260 m.y. B.P. in the mid Permian [17] (Fig. 2). During the Permian and Triassic subsidence was mainly restricted to two narrow parallel linear troughs which Brunet and Le Pichon [18] interpret as rifts resulting from crustal extension. On the other hand, the post-Triassic thermal subsidence beginning about 200 m.y. B.P. (Fig. 2) has been much more widespread giving the basin its present bowl shape. A similar situation exists in the Sirte Basin of Libya which was the site of active horst and graben tectonics along three parallel trends from the Cretaceous through the Miocene [19].

The purpose of this study is to systematically investigate the effects of a finite-duration rifting event. First a technique will be described for tracing the development of a sedimentary basin through an extended rifting event. This method, 
allows an arbitrary rifting history and basin geometry to be specified and also allows the effects of lateral heat conduction to be determined. The effects of various-length rifting times on the subsidence rates and heat flow will then be investigated for a number of simple model basins. Finally the manner in which this parameter interacts with others such as the rigidity of the lithosphere to produce a variety of stratigraphic patterns will also be examined.

\section{Computational method}

A method developed by Steckler [3,9] to obtain an analytic solution for the instantaneous rifting case with horizontal heat conduction can be adapted to trace the temperature structure of the lithosphere through a finite-length rifting event. We will first outline the method and then explain how it can be extended to the finite-length rifting case.

The temperature structure of the extended lithosphere is governed, assuming no variations along strike, by the two-dimensional heat flow equation:

$\frac{\partial^{2} T}{\partial x^{2}}+\frac{\partial^{2} T}{\partial z^{2}}=\frac{1}{K} \frac{\partial T}{\partial t}$

where $T=T(x, z, t)$ is the temperature, $x$ and $z$ are the horizontal and vertical coordinates respectively, and $K$ is the thermal diffusivity. The lithosphere is assumed to be divided into a series of narrow blocks. The temperature distribution due to the thermal perturbation of one block may be written:

$T(x, z, t)=X(x, t) \cdot Z(z, t)$

where $X(x, t)$ and $Z(z, t)$ are the solutions of the one-dimensional heat flow equations in $x$ and $z$, respectively.

The solution in the vertical direction is simply the case considered by McKenzie [2] and the solution can be written as:

$Z(z, t)=T_{0} \frac{z}{a}+\sum_{n=1}^{\infty} A_{n} \sin \left(\frac{n \pi z}{l}\right) \mathrm{e}^{-n^{2} t / \tau}$

where $T_{0}$ is the asthenosphere temperature, $l$ is the equilibrium thickness of the lithosphere and $\tau$ is the thermal time constant of the lithosphere. The $A_{n}$ 's are the Fourier series coefficients of the temperature anomaly due to the extension. Thus the vertical solution can be written in terms of a steady state equilibrium solution and a thermal transient due to the extension which, following Watts et al. [5], will be designated $\zeta(z, t)$ in the following development:

$\zeta(z, t)=\sum_{n=1}^{\infty} A_{n} \sin \left(\frac{n \pi z}{l}\right) \mathrm{e}^{-n^{2} t / \tau}$

The solution of the horizontal term $X(z, t)$ follows Steckler [3]. The boundary condition is that the lithosphere is continuous and the solution is that of heat flowing into a semi-infinite medium [20]:

$X(x, t)=\frac{1}{2 \sqrt{\pi k t}} \int_{-\infty}^{\infty} X\left(x^{\prime}, 0\right) \mathrm{e}^{-\left(x-x^{\prime}\right)^{2} / 4 k T} \mathrm{~d} x^{\prime}$

The initial condition for a single block is that $X=1$ between $a$ and $b$, the limits of the block, and $X=0$ otherwise. Thus:

$X(x, t)=\frac{1}{2}\left[\operatorname{erfc}\left(\frac{x-a}{\sqrt{4 k t}}\right)-\operatorname{erfc}\left(\frac{x-b}{\sqrt{4 k t}}\right)\right]$

The total solution for the temperature distribution due to a single block is therefore:

$$
\begin{aligned}
T(x, z, t)= & T_{0} \frac{z}{l}+\frac{1}{2}\left[\operatorname{erfc}\left(\frac{x-a}{\sqrt{4 k t}}\right)\right. \\
& \left.-\operatorname{erfc}\left(\frac{x-b}{\sqrt{4 k t}}\right)\right] \cdot \zeta(z, t)
\end{aligned}
$$

Since the heat flow equation is linear, the law of superposition can be used to determine the temperature distribution following an extension event involving a number of blocks, each of which may be "stretched" by different amounts:

$$
\begin{aligned}
T(x, z, t)= & T_{0} \frac{z}{l}+\frac{1}{2} \sum_{i=1}^{N}\left[\operatorname{erfc}\left(\frac{x-x_{i}}{(4 k t)}\right)\right. \\
& \left.-\operatorname{erfc}\left(\frac{x-x_{i+1}}{(4 k t)}\right)\right] \zeta_{i}(z, t)
\end{aligned}
$$

where $x_{i}$ and $x_{i+1}$ are the positions of the edges of block $i, \zeta(z, t)$ is the transient solution (equation (4)) for that block and $N$ is the total number of blocks. It is assumed in equation (8) that the temperature anomaly at time $T=0$ is known and 
that heat transfer occurs only by conduction. This requires that no further extension of the lithosphere occurs during the cooling. This solution is thus appropriate for the instantaneous extension model and has been used to investigate the influence of lateral effects on that model by Steckler [9].

The technique can be adapted to trace the thermal structure of the lithosphere through a finite-length rifting event by considering that the extension, rather than being continuous, occurs in a series of discrete, short rifting events. Each lithospheric block is extended by an appropriate small amount at the beginning of the first rifting event and is allowed to cool through the time step. The temperature structure at the end of the cooling period is determined from equation (8) and is used as the initial temperature structure for the next rifting event. The temperature structure enters the mathematical treatment through the values of the $A_{n}$ 's in equations (3) and (4). However, after the first rifting event the pre-rift temperature gradient is no longer linear and the expression given by Royden and Keen [21] for the $A_{n}$ 's is not applicable. Therefore, after each rifting event, a Fourier sine transform is performed on the temperature anomaly $\left(T(x, z, t)-T_{0} z / l\right)$ to determine the values of the $A_{n}$ 's for the subsequent cooling period.

There are two constraints on the acceptable length for the rifting steps. They must be short enough that the procedure approximates continuous rifting, yet long enough that the laterally spreading heat has an effect at the center of the adjacent block. It was found that a time step of 0.5 m.y. is acceptable, providing the post-rift width of the blocks is less than about $10 \mathrm{~km}$. The surface heat flow and subsidence obtained by this technique using a "one-box" model (no lateral heat flow effects) agree with the results of Jarvis and McKenzie [8] to better than 1\%.

\section{Model results}

The effects of an extended rifting event on the development of a simple sediment free basin are shown in Figs. 3, 4, and 5. The values used for model parameters are summarized in Table 1 and were chosen to give an internally consistent, iso-
TABLE 1

Values of model parameters

\begin{tabular}{lll}
\hline Parameter & Symbol & Value \\
\hline Lithospheric thickness & $l$ & $125 \mathrm{~km}$ \\
Crustal thickness ${ }^{\mathrm{a}}$ & $t_{\mathrm{c}}$ & $31.2 \mathrm{~km}$ \\
Crustal density & $\rho_{\mathrm{c}}$ & $2.8 \mathrm{~g} / \mathrm{cm}^{3}$ \\
Mantle density & $\rho_{\mathrm{m}}$ & $3.33 \mathrm{~g} / \mathrm{cm}^{3}$ \\
Sediment density & $\rho_{\mathrm{s}}$ & $2.4 \mathrm{~g} / \mathrm{cm}^{3}$ \\
Water density & $\rho_{\mathrm{w}}$ & $1.03 \mathrm{~g} / \mathrm{cm}^{3}$ \\
$\begin{array}{l}\text { Coefficient of thermal } \\
\text { expansion a }\end{array}$ & $\alpha$ & $3.4 \times 10^{-5}{ }^{\circ} \mathrm{C}^{-1}$ \\
Asthenospheric temperature & $T_{0}$ & $1333^{\circ} \mathrm{C}$ \\
Thermal diffusivity & $K$ & $0.008 \mathrm{~cm}^{2} / \mathrm{s}$ \\
Thermal conductivity & $\kappa$ & $0.0075 \mathrm{cal} / \mathrm{deg} \mathrm{cm} \mathrm{s}$ \\
Lithospheric thermal time & & \\
$\quad$ constant $\left(a^{2} / \pi^{2} K\right)$ & $\tau$ & $62.7 \mathrm{~m} . \mathrm{y}$.
\end{tabular}

a The values of these parameters have been chosen so that old (125 km thick) continental lithosphere at sea level is in isostatic balance with oceanic lithosphere containing a $5-\mathrm{km}$ thick crust which has a ridge crest depth of $2500 \mathrm{~m}$ and subsides toward a final depth of $6400 \mathrm{~m}$.

statically balanced system $[9,22]$.

Cross-sections showing the development of the rift basin for different extension times are shown in Fig. 3. The left half of each basin has been replaced by the case of instantaneous rifting with lateral heat flow to facilitate comparison. The development of the basin for instantaneous rifting and no lateral heat flow (simple McKenzie model) is also shown as dashed lines. The subsidence and surface heat flow are plotted as functions of time in Figs. 4 and 5 respectively for locations A, B and $\mathrm{C}$ noted at the bottom of Fig. 3. Location $\mathrm{A}$ is just outside the rift, $\mathrm{B}$ is near the base of the hinge zone and $\mathrm{C}$ is near the center of the basin. It can be seen from Figs. 3 and 4 that the loss of heat during the syn-rift period causes significant deviation from the instantaneous case in the immediate post-rift period for extension times as short as 5 m.y. As the extension time increases, these differences become greater and persist longer.

The effects of the finite rifting are dependent on position within the basin. The effects are greatest near the hinge zone where the horizontal temperature gradients are the greatest and decrease towards the center of the basin. The subsidence and heat flow in the center of a basin with 


\section{BASIN MODEL}

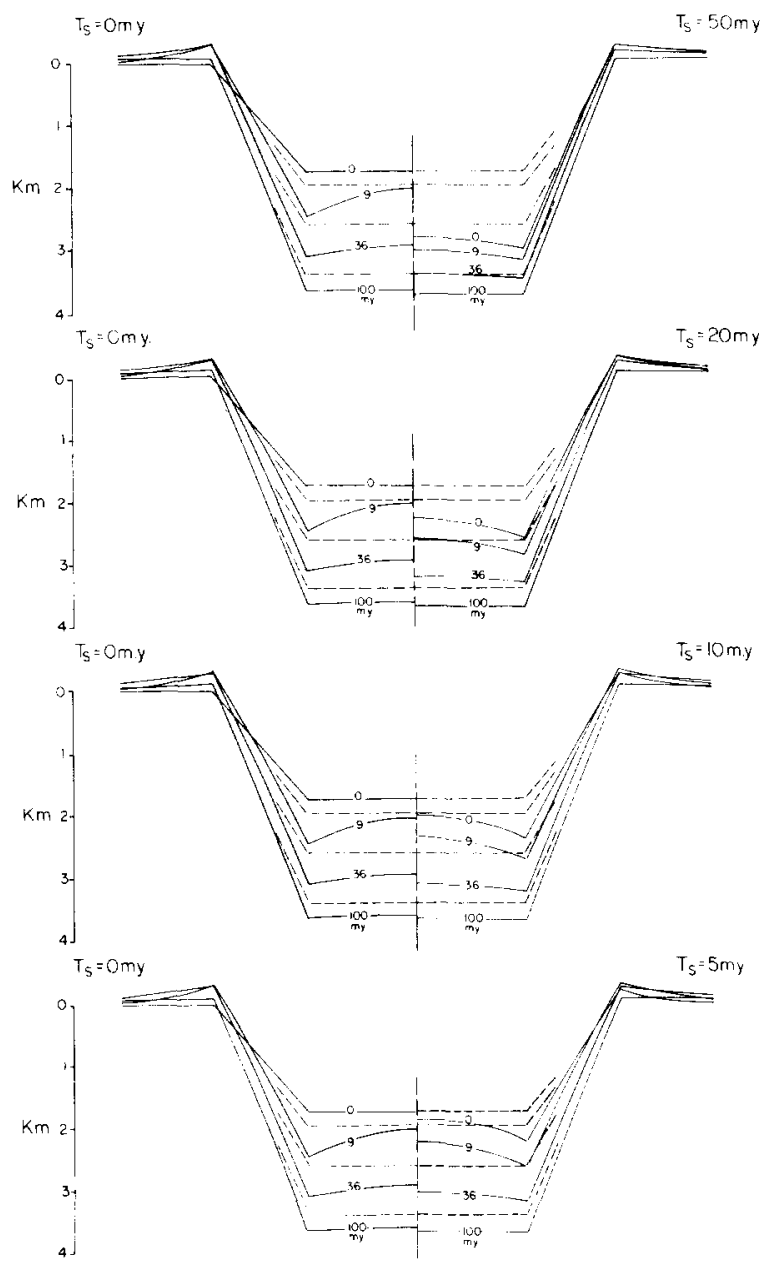

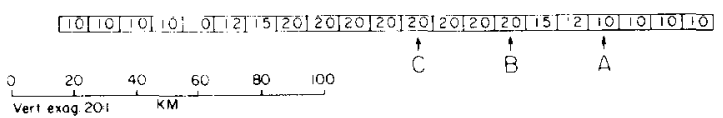

Fig. 3. Tectonic subsidence for a simple model basin showing the effects of a finite-length rifting event. The left side of the basin is the same for each cross-section and shows the development of the basin for instantaneous rifting, while the right-hand side shows the results for different rifting times, $T_{\mathrm{s}}$. In both cases the calculations shown in solid lines include lateral heat flow. The dashed lines show the development of the basin for instantaneous rifting and no lateral heat flow. Time $t=0$ is taken as the end of the rifting event in all cross-sections. The numbers under the cross-sections show the value of the stretching parameter $\beta$ for each lithospheric block. $A, B$, and $C$ are locations discussed in text and subsequent figures.

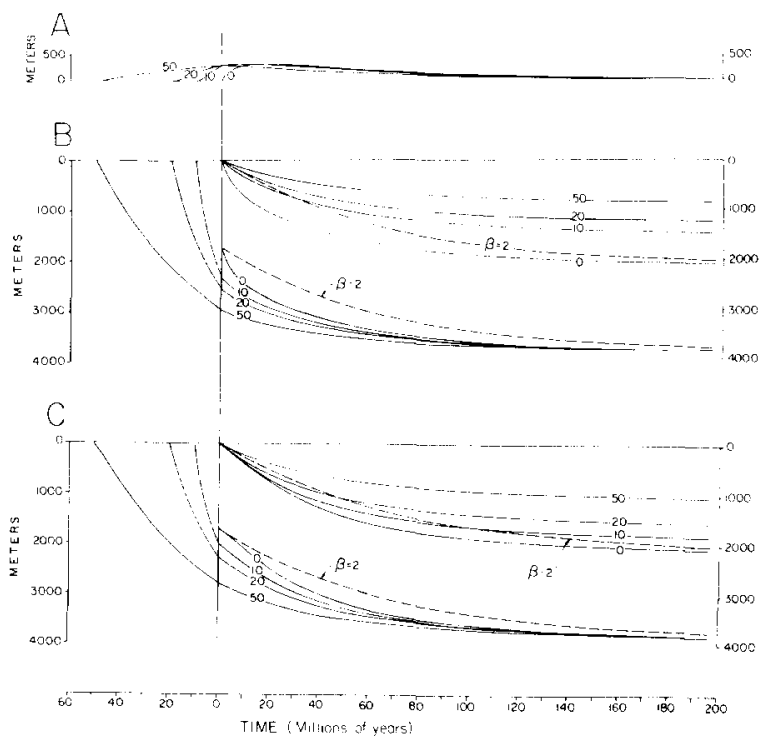

Fig. 4. Subsidence curves for the three locations A, B, and C of the basin shown in Fig. 3 for rifting times, $T_{s}$, of 0, 10, 20 and $50 \mathrm{~m}$.y. Dashed curve labelled $\beta=2$ shows results of instantaneous one-dimensional model [2]. Subsidence for locations B and $C$ is shown both including syn-rift subsidence and normalized to show only post-rift subsidence. In all cases the basin is assumed to be water filled.

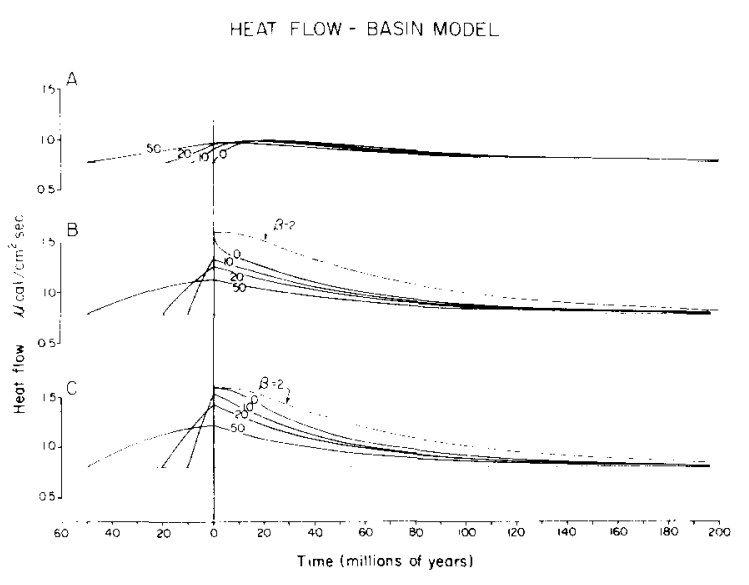

Fig. 5. Surface heat flow as a function of time for the three locations $\mathrm{A}, \mathrm{B}$, and $\mathrm{C}$ of the basin shown in Fig. 3 for rifting times, $T_{\mathrm{s}}$, of $0,10,20$ and $50 \mathrm{~m} . \mathrm{y}$. Dashed curve labelled $\beta=2$ shows results of instantaneous one-dimensional model [2]. 
uniform extension parameter $\beta$ will approach Jarvis and McKenzie's [8] results as the basin becomes very wide. However, with a few notable exceptions, such as the northern Red Sea (which is a developing continental margin and likely to have significant variations in the extension parameters within the basin), few rifts are wider than the 80-km model rift basin considered here. Sedimentary basins are commonly $200-300 \mathrm{~km}$ wide. However, much of a mature basin would be expected to be underlain by unrifted crust and lithosphere which has subsided as the result of crustal flexure [5] (also see Fig. 11). Thus the results near the center of the model basin (location C) can be considered reasonable minimum estimates of the effects of a finite length extension event.

\section{SUBSIDENCE}

$\mathrm{B}$

\section{BASIN MODEL}
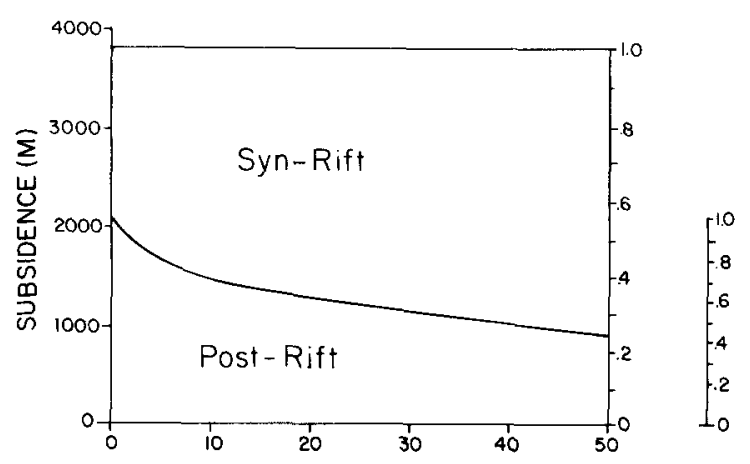

C

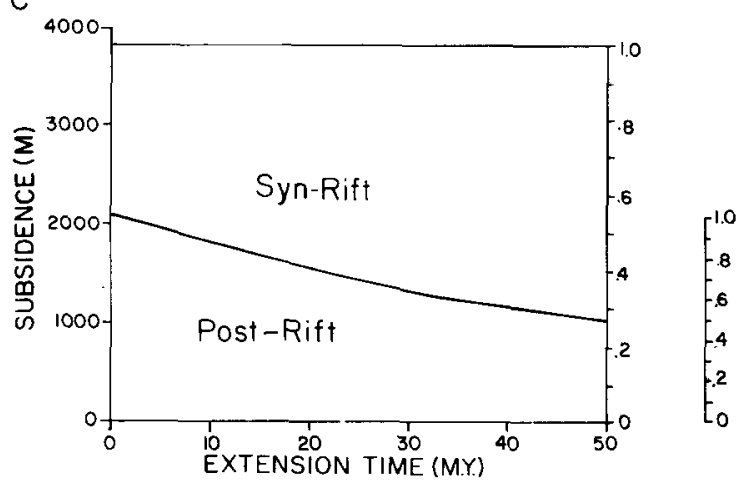

Fig. 6. Relationship between syn- and post-rift subsidence as a function of duration of rifting event for locations $B$ and $C$ of the basin shown in Fig. 3. Scale at far right gives post-rift subsidence normalized against instantaneous case.
The effect of the loss of heat from the rifted area during the extended rifting event is to increase the syn-rift subsidence at the expense of the post-rift subsidence (Fig. 6). For the basin considered here, the post-rift subsidence is decreased by a minimum of $10-15 \%$ for a $10-m$.y. extension event and by about $25 \%$ for a $20-\mathrm{m}$.y. extension event. The surface heat flow within the basin is always less than that predicted by the McKenzie [2] model (Figs. 5, 7), due to the lateral flow of heat out of the basin as well as vertical cooling during the syn-rift stage. The lateral heat flow results in increased heat flow and thermal expansion causing significant uplift in the regions flanking the rift. Note that no crustal radioactive com-

\section{MAXIMUM HEAT FLOW ANOMALY BASIN MODEL}
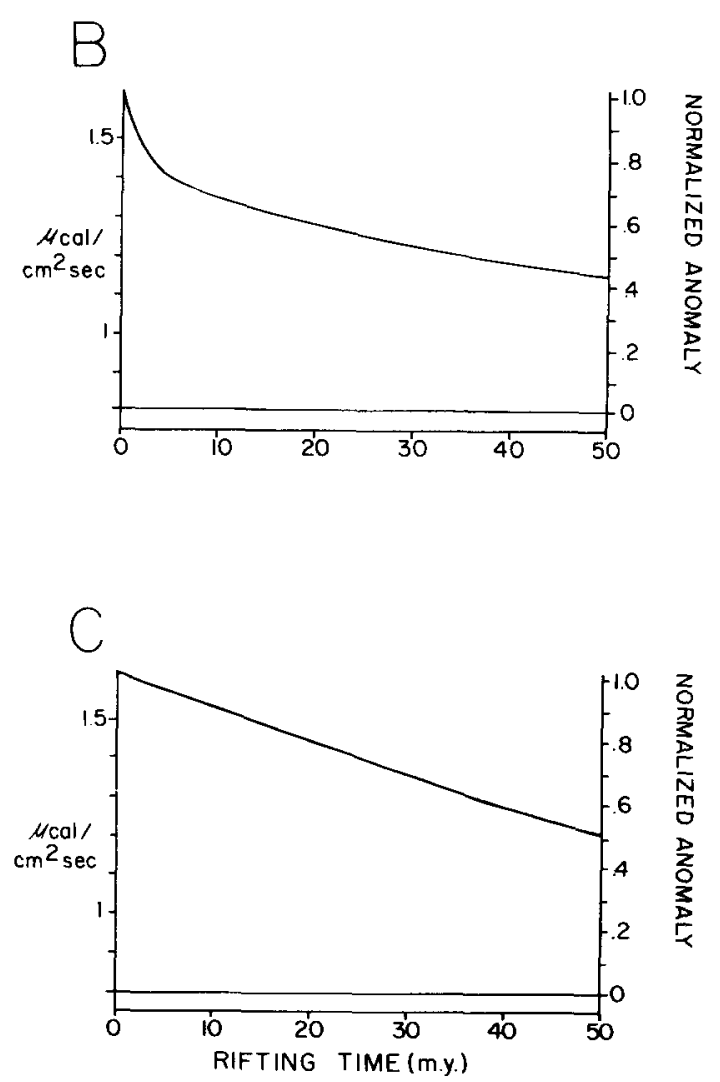

Fig. 7. Maximum surface heat flow as a function of duration of rifting event for locations B and C of the basin shown in Fig. 3. 


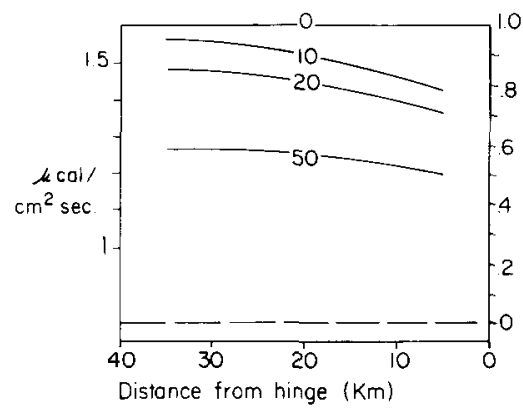

\section{THERMAL SUBSIDENCE}

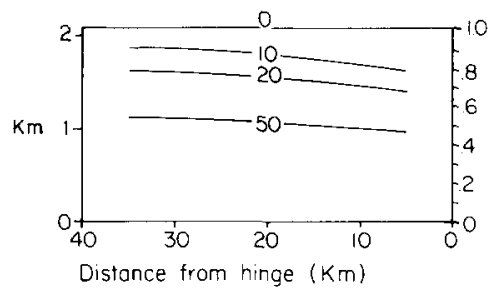

Wide Hinge
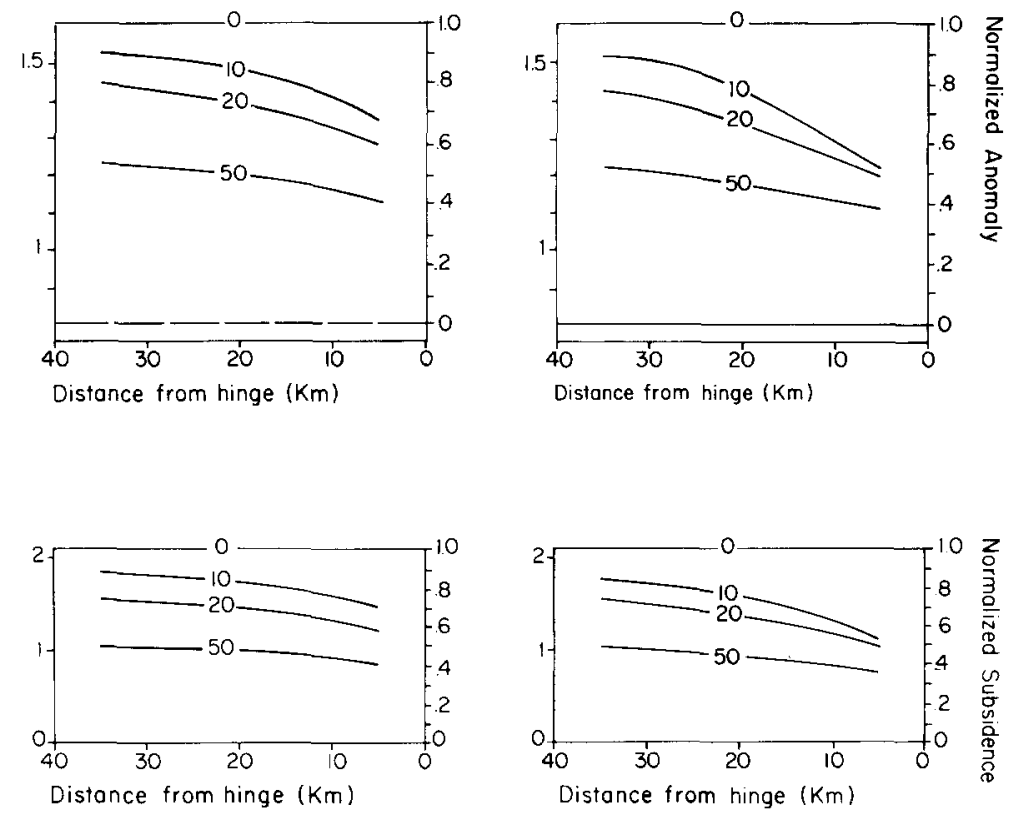

Model Basin

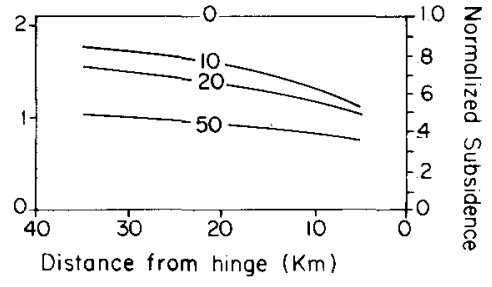

Narrow Hinge

Fig. 8. Maximum heat flow and thermal (post-rift) subsidence as a function of distance from the base of the hinge zone for three basins. The case labelled "Model Basin" is the basin shown in Fig. 3. The "Wide Hinge" basin differs from it only in that the width of the hinge zone has been increased to $40 \mathrm{~km}$ and the "Narrow Hinge" basin differs from it only in that the basin floor ( $\beta=2)$ is immediately juxtaposed to unextended lithosphere.

ponent has been included in the heat flow calculations in order to show the effects of the finite rifting time on the mantle heat flow component. When crustal radioactivity is included, it is possible, because of the thinner crust within the basin, to have the unusual and seemingly paradoxical situation of a surface heat flow minimum over a heated region.

The effects of a finite-length rifting event would be expected to depend on the geometry of the rift basin and on the value of the extension parameter, $\beta$. The effects of basin geometry are illustrated in Fig. 8 which shows the magnitude of the thermal subsidence and maximum heat flow anomaly calculated for different values of $T_{\mathrm{s}}$ as a function of distance from the base of the hinge zone for the model basin (Fig. 3) and for two basins which differ from it only in the width of the hinge zone.
The width of the hinge zone has been increased from $20 \mathrm{~km}$ to $40 \mathrm{~km}$ in the "wide hinge" basin, while in the "narrow hinge" case the basin floor $(\beta=2)$ is directly juxtaposed against unextended lithosphere $(\beta=1)$. The width of the hinge zone, and thus the horizontal thermal gradient, has a large effect on the subsidence pattern and heat flow, particularly near the hinge zone and for extension times of less than 20 m.y. However, for the models which we have considered, the differences are minimal near the center of the basin and the subsidence and heat flow at position $\mathrm{C}$ are nearly the same for all three cases.

Fig. 9 compares the results obtained for the model basin (Fig. 3) with those obtained for basins with the same geometry but in which the extension parameter $\beta$ within the basin was set at 1.5 (50\% extension) and 4 (300\% extension). Although the 
THERMAL SUBSIDENCE
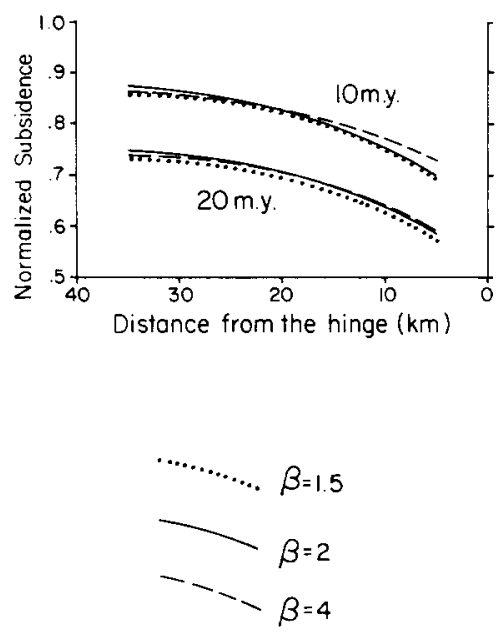

HEAT FLOW
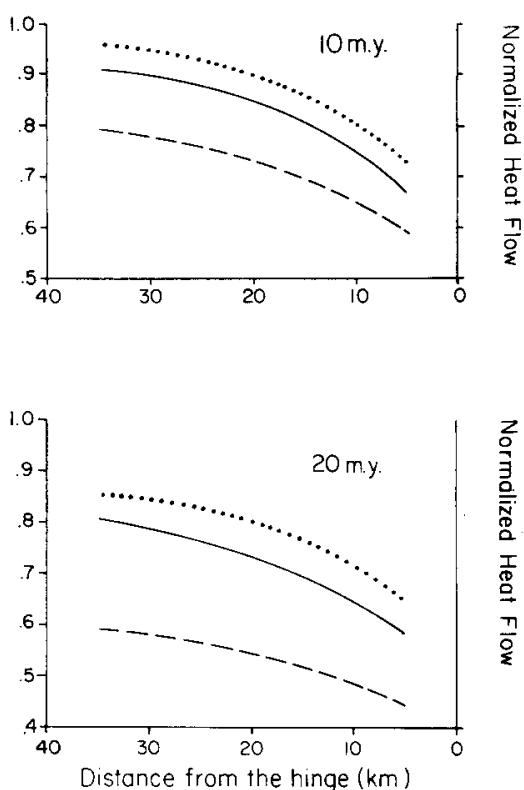

Fig. 9. Maximum heat flow and thermal (post-rift) subsidence as a function of distance from the base of the hinge zone for basins with geometry of the basin shown in Fig. 3, but with varying value of the stretching parameter, $\beta$. Results are normalized against results of instantaneous, one-dimensional case [2]. Results are shown for extension times of 10 m.y. and 20 m.y.

total amount of thermal subsidence depends strongly on $\beta$, when it is normalized against the post-rift subsidence predicted by the McKenzie [2] model, the results are almost identical to those for the model basin with $\beta=2(100 \%$ extension). The effect on the normalized heat flow is much more dependent on the value of $\beta$ (Fig. 9) with the greatest decrease occurring for large values of $\beta$.

The effect of the finite-duration rifting event is to increase the syn-rift subsidence at the expense of the post-rift. This will result in flatter post-rift subsidence curves which will result in underestimating the amount of extension, if observed subsidence curves are compared with theoretical curves generated using the one-dimensional rifting model [2], as is often done in studies of specific basins. Fig. 10 shows post-rift subsidence curves from locations B and C of Fig. 3 (solid curves) along with subsidence curves predicted by the simple model [2] for a range of $\beta$ values (dotted curves). A $\beta$ value of $1.25-1.5$, rather than the actual value of 2 , would probably be chosen as best matching the shape of all of the subsidence curves, particu-

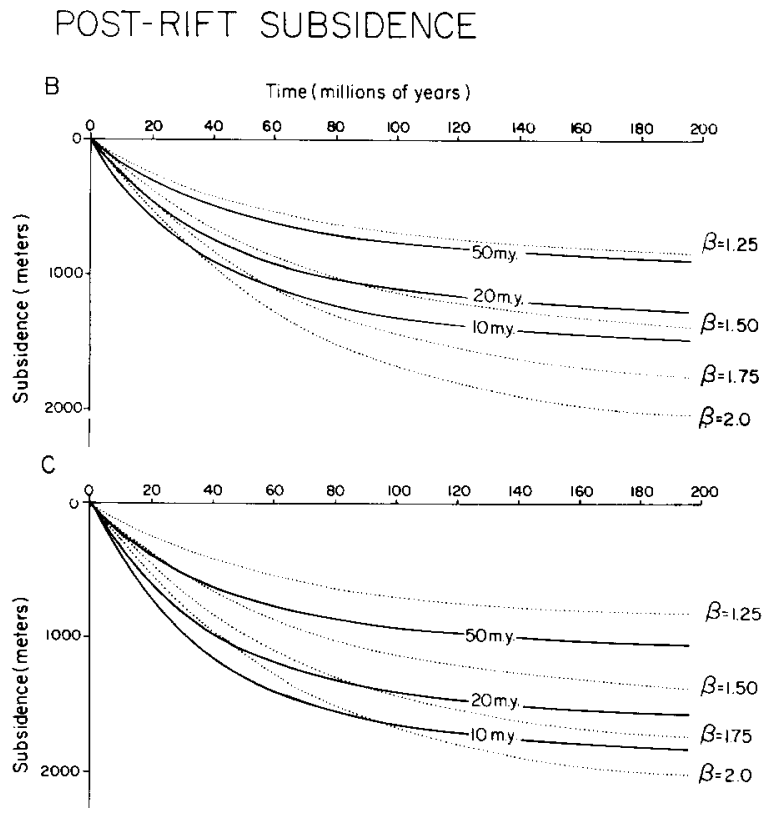

Fig. 10. Post-rift subsidence curves for locations $\mathrm{B}$ and $\mathrm{C}$ of the basin shown in Fig. 3 for extension times of 10, 20 and 50 m.y. (solid lines) compared with subsidence curves resulting from the instantaneous one-dimensional model (dotted lines). 
larly if the later portion of the subsidence curve (upper portion of the sediment column) is used to determine $\beta$.

Fig. 10 also shows that the subsidence curves cut across $\beta$-curves, with the basin subsiding more rapidly in its early history and more slowly in the later history than predicted by the McKenzie [2] model. This behavior reflects the lateral transport of heat out of the basin and is characteristic of models which include lateral heat flow. It is also a pattern which can be observed in actual subsidence data [23]. These deviations from the $\beta$-curves could mistakenly be interpreted as the effect of sea level variations. However, they may be distinguished because they are a systematic change in the shape of the curve, rather than a perturbation of limited extent upon it as are the sea level variations discussed, for example, by Watts and Steckler [24].

\section{Effects of lithospheric rigidity}

The model basins discussed above have all been assumed to be sediment free in order to examine the effects of finite extension times on the driving tectonic subsidence independent of other complicating factors. If the sediments are compensated in a local "Airy" fashion then the results obtained can be directly applied to the backstripped subsidence curves.

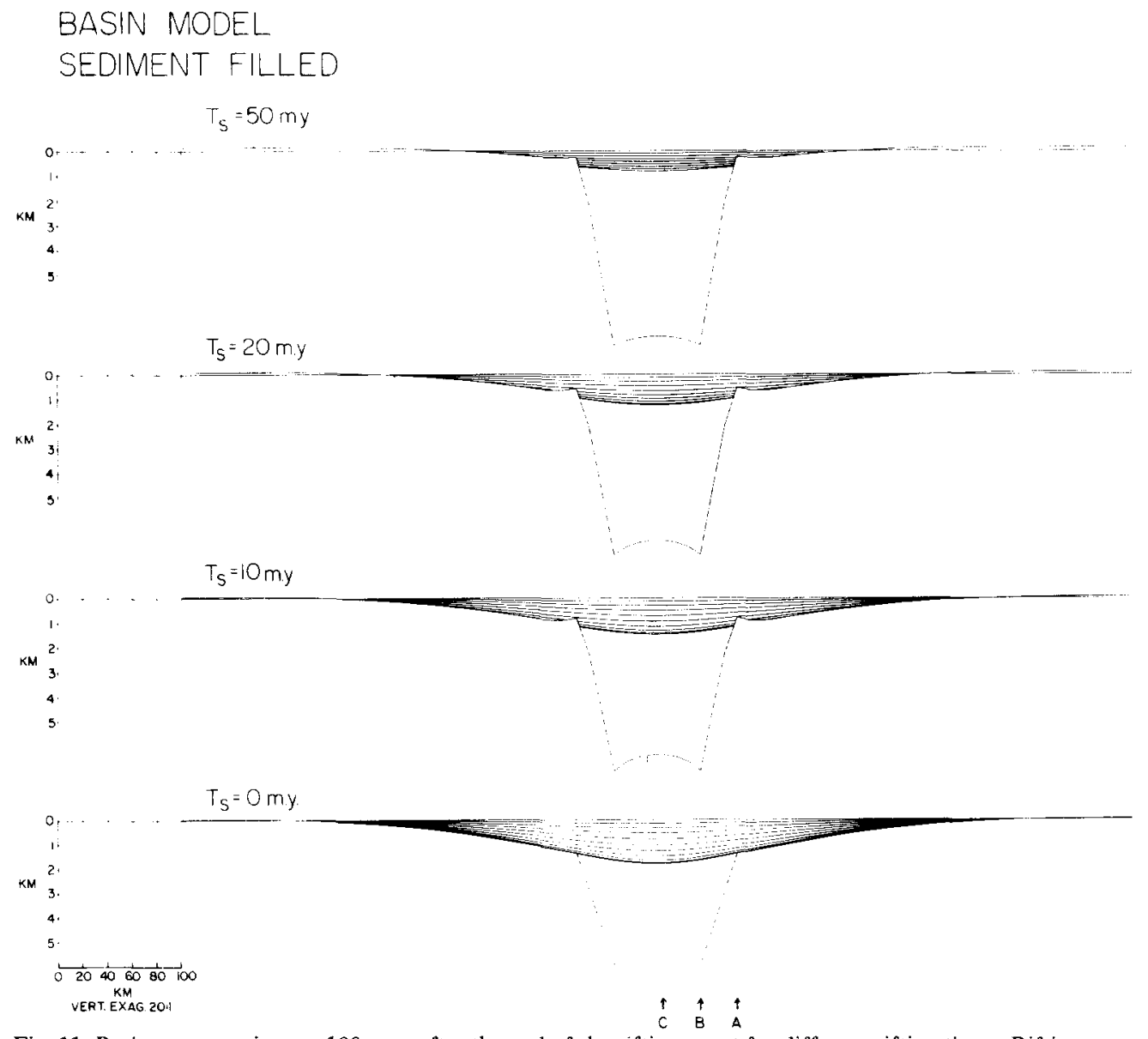

Fig. 11. Basin cross-sections at $100 \mathrm{~m} . \mathrm{y}$. after the end of the rifting event for different rifting times. Rifting parameters are the same as for the basin in Fig. 3. Syn-rift sediments are assumed to be compensated in a local (Airy) fashion and post-rift sediments in a regional (flexural) fashion. Post-rift stratigraphic horizons are shown at integer square root of time intervals after the end of rifting. 
However, the sediments which accumulate in a sedimentary basin represent a load on the lithosphere which would be expected to respond, at least during the post-rift stage, by flexure [5]. Fig. 11 shows cross-sections throught the model basin (Fig. 3) at 100 m.y. after the end of the rifting event for four different-length rifting events including the effects of sediment loading. In these models, the syn-rift sediments are assumed to be compensated in a local, Airy manner reflecting the active faulting occurring during that stage, and the post-rift sediments are assumed to be compensated in a regional manner through lithospheric flexure. The flexural rigidity was defined by the depth to the $450^{\circ}$ isotherm [25] and thus varies in time and in space across the basin.

The effect of the lithospheric rigidity is to distribute the compensation of the load so that subsidence occurs outside the rifted and heated area. Thus the post-rift subsidence is reduced within the rifted portion of the basin further flattening the subsidence curves, while significant subsidence can

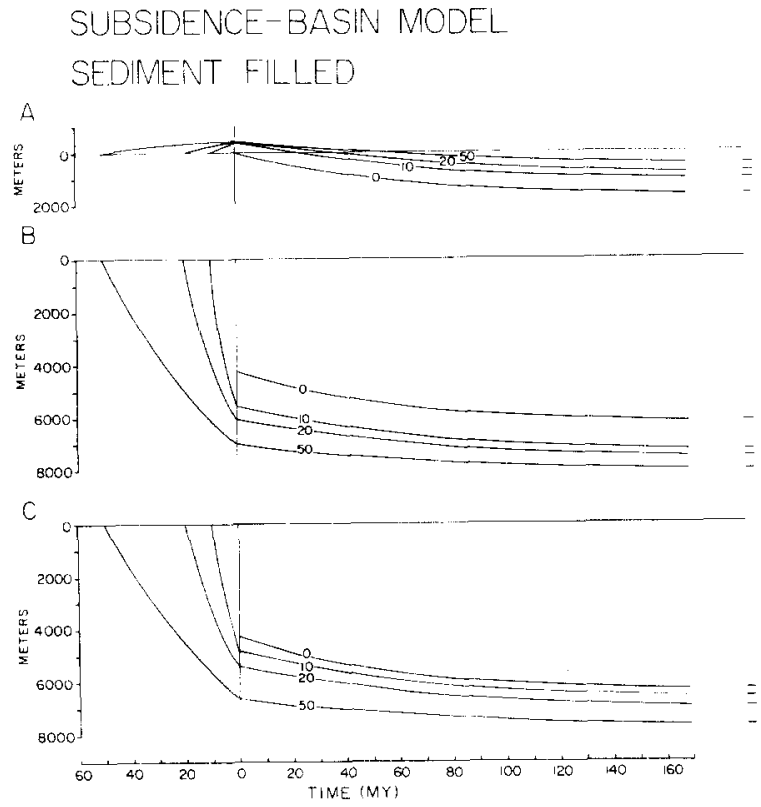

Fig. 12. Subsidence curves for the three locations A, B, C of basins shown in Fig. 11. These locations have the same relationship to the rifted portion of the basin as the subsidence curves shown in Fig. 4. Short horizontal lines at the far right show the final depth of the basin for each case considered.

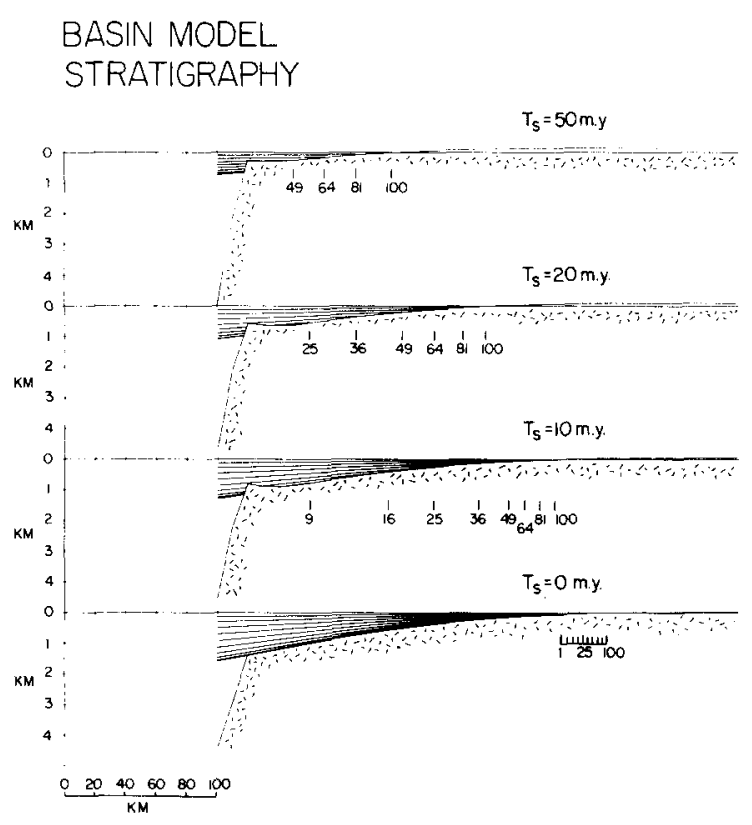

Fig. 13. Detail of cross-sections shown in Fig. 12 illustrating widening of basin with time and nature of onlap onto unextended basement flanking rift. Stratigraphic horizons are at integer square root of time intervals following the end of rifting and location of pinch out of each horizon is noted.

occur at position $\mathrm{A}$ on the unextended lithosphere (Fig. 12).

The nature of the flexurally controlled portion of the basins shown in Fig. 11 can be seen more clearly in Fig. 13. Both the width of the basin and the timing and nature of the onlap onto the surrounding regions are dependent on the duration of the rifting event. Sediments are immediately deposited over a wide area outside the rift basin in the case of instantaneous rifting, but the size of the basin increases only slightly with time, producing only a very limited amount of onlap. With increasing extension times, expansion of the basin out of the rifted region is delayed for a time comparable to the extension time and the width of the basin decreases systematically. However the progressive onlap onto the unrifted area becomes much more pronounced.

The models also predict that the syn- and postrift sediments may be separated by an unconformity. For non-zero extension times, there is a delay in subsidence and actually a slight uplift of 


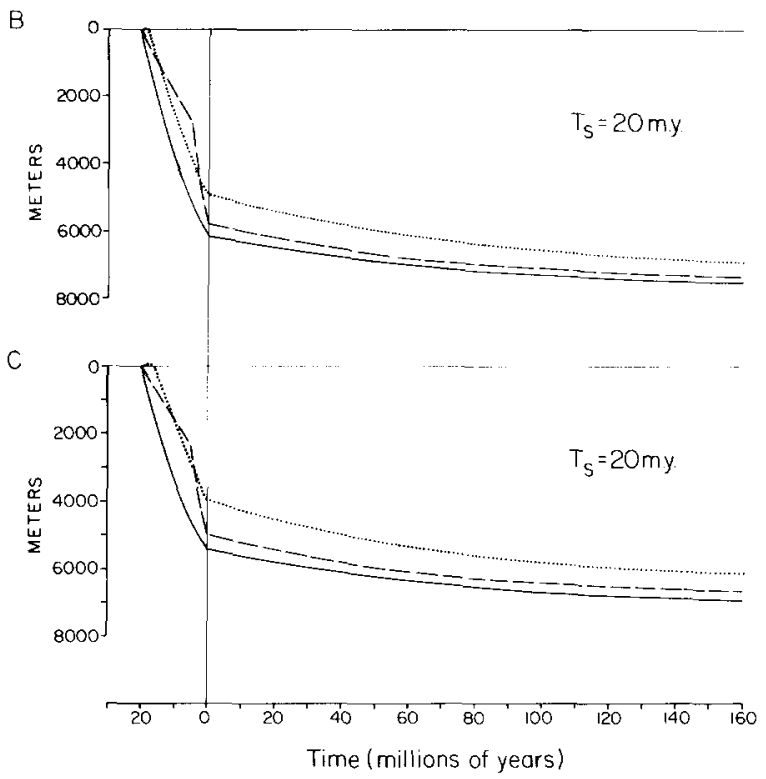

Fig. 14. Subsidence curves for locations $B$ and $C$ of model basin (Figs. 3, 11) with $T_{s}=20 \mathrm{~m}$.y., but with different stretching histories. Solid line shows case where $\beta$ increases linearly through the rifting event. Dashed line shows case where $25 \%$ of extension occurs during the first $15 \mathrm{~m} . \mathrm{y}$. and $75 \%$ of extension occurs in the last $5 \mathrm{~m} . \mathrm{y}$. of rifting. Dotted line shows case where lithospheric thinning is twice that implied by the crustal extension.

the basin for a period of $2-4$ m.y. following the end of rifting. This slight uplift is due to the change from local to regional compensation combined with reduced tectonic subsidence within the basin and the fact that the rift shoulders are still being uplifted by heat flowing out of the basin. The uplift is of quite small magnitude $(<50 \mathrm{~m})$ and thus it is open to question whether an unconformity would be formed in a real basin where the boundary faults may still be subject to motion following the end of active rifting. However, it does provide a mechanism for producing the "breakup" unconformity first described by Falvey [26] and since reported at a number of continental margins (e.g. [27,28]).

It can be readily seen from fig. 11 that as the extension time becomes greater, the syn-rift sediments come to occupy an increasingly large portion of the sediment column. With a 20-m.y. extension time the syn-rift sediments represent $77 \%$ of the sediments which finally accumulate at position $\mathrm{C}$ near the center of the basin. This is probably an unrealistically large ratio of syn- to post-rift sediments. Fig. 14 shows that the amount of syn-rift sediments can be slightly, but not significantly, reduced by concentrating a majority of the extension near the end of the rifting stage, rather than having $\beta$ increase linearly throughout rifting as in all the prior calculations. In the case shown by the dashed curves in Fig. 14, 25\% of the extension occurs in the first $15 \mathrm{~m} . \mathrm{y}$. and $75 \%$ occurs in the final $5 \mathrm{~m} . y$. This has the effect of slightly decreasing the syn-rift subsidence and slightly increasing the post-rift subsidence. However, over $70 \%$ of the sediments in the basin still accumulated during rifting.

Fig. 14 also shows as dotted curves the effects on the subsidence of using a two-layer model in which the lithosphere is thinned by an amount greater than that required by the crustal extension. This model implies that the extension and lithospheric thinning is not simply the passive result of extensional forces applied elsewhere, but rather involves active heating from below. In the model for which the subsidence curves are shown in Fig. 14 , it is assumed that the lithospheric thinning is twice the crustal thinning. The additional heat put into the lithosphere and the resulting thermal expansion reduce the amount of syn-rift subsidence, although not nearly as much as for an instantaneous two-layer rifting model, because heat is rapidly conducted laterally out of the basin. For the model basin considered here (crustal thinning factors as in Fig. 3), syn-rift sediments represent $63 \%$ of the sediments which finally accumulate in the basin. An additional interesting feature of this particular model is that the initial response to the extension and lithospheric thinning is uplift which lasts for several million years and has an amplitude of a few hundred meters. Thus, the onset of rifting would be predicted to be associated with a well developed unconformity.

Sediment compaction, which has not been included in the models shown here, will serve to somewhat decrease the thickness of syn-rift sediments. Sediments expel pore water and become more densely packed as the overburden pressure increases. Thus the deeply buried syn-rift sedi- 
ments will be denser and occupy less volume than the less deeply buried post-rift sediments. However, this effect will not be great enough to change the prediction that the sediments which accumulate in the rift during the active stage will be significantly thicker than those which accumulate during the wider flexurally controlled post-rift stage of the basin's evolution.

\section{Conclusions}

The early stages of the evolution of a sedimentary basin play a major role in shaping the development of the basin. Specifically, the duration, as well as the location and nature, of the rifting event responsible for the creation of the basin has a major influence on the subsidence rates, total amount of sediments, heat flow and stratigraphic patterns, and these effects are still being manifest at least $100 \mathrm{~m} . \mathrm{y}$. after the end of the rifting event.

The effect of an extended rifting phase is to transfer a portion of the heat loss, which is all post-rift in the instantaneous models, to the syn-rift period. As a result, additional syn-rift subsidence occurs with less subsidence and slower subsidence rates during the post-rift period. When the effects of lateral heat conduction are considered, the post-rift subsidence near the center of an $80-\mathrm{km}$ wide model rift is decreased by $10-15 \%$ for a $10-$ m.y. rifting event and by $25 \%$ for a $20-\mathrm{m}$.y. rifting event. The effects become even larger as the margins of the rift basin are approached. The final width of the sedimentary basin and the stratigraphic patterns in the flexurally controlled portions of the basin are also greatly influenced by the nature and duration of the rifting event.

The lateral conduction of heat has a characteristic effect on the shape of subsidence curves with more rapid subsidence in the early post-rift stage followed by slower subsidence so that the subsidence curves cut across those generated using the one-dimensional model. As a result of this effect and the decrease in post-rift subsidence caused by even relatively short rifting events, it is probably not valid to use " $\beta$-curves" generated from the instantaneous stretching model (Fig. 1) to analyze the subsidence of sedimentary basins.
More sophisticated models can reproduce most of the observed characteristics of sedimentary basins. However, these models introduce additional parameters which can be "juggled" to fit a particular data set. Thus additional geological control to provide cross-checks on the model results is necessary to determine the extent to which the modeling actually conforms to what is observed in nature. However, with adequate geologic control, careful modeling should be able to give reasonable constraints on the thermal structure and development of sedimentary basins and continental margins.

\section{Acknowledgements}

G. Bond, W. Pitman, M. Steckler, and J. Thorne reviewed the manuscript. The modeling technique developed in this paper depends upon previous work by $\mathrm{M}$. Steckler on lateral heat conduction and by $J$. Bodine on flexure of a non-uniform lithosphere, a debt which I am very pleased to acknowledge. This work was supported by $\mathrm{Na}$ tional Science Foundation grant OCE 79-19241 and a grant to Columbia University by Curtis, Mallet-Prevost, Colt and Mosle.

\section{References}

1 N.H. Sleep, Thermal effects of the formation of Atlantic continental margins by continental breakup, Geophys. J.R. Astron. Soc. 24, 325-350, 1971.

2 D.P. McKenzie, Some remarks on the development of sedimentary basins, Earth Planet. Sci. Lett. 40, 25-32, 1978.

3 M.S. Steckler, The thermal and mechanical evolution of Atlantic-type continental margins, 261 pp., Ph.D. Thesis, Columbia University, New York, N.Y., 1981.

4 M.S. Steckler and A.B. Watts, The Gulf of Lion: Subsidence of a young continental margin, Nature 287, 425-429, 1980.

5 A.B. Watts, G.D. Karner and M.S. Steckler, Lithospheric flexure and the evolution of sedimentary basins, Philos. Trans. R. Soc. London Ser. A, 305, 249-281, 1982.

6 C.E. Keen, C. Beaumont and R. Boutilier, Preliminary results from a thermo-mechanical model for the evolution of Atlantic-type continental margins, Oceanol. Acta (Proc. 26th Int. Geol. Congr.), pp. 123-128, 1981.

7 L. Royden, J.G. Sclater and R.P. Von Herzen, Continental margin subsidence and heat flow: important parameters in 
formation of petroleum hydrocarbons, Am. Assoc. Pet. Geol. Bull. 64, 173-187, 1980.

8 G.T. Jarvis and D.P. McKenzie, Sedimentary basin formation with finite extension rates, Earth Planet. Sci. Lett. 48, $42-52,1980$.

9 M.S. Steckler, Two-dimensional considerations in the subsidence of continental margins, Geophys. J. Geophys. Res. (in press).

10 L.F. Jansa, F.M. Gradstein, F.M. Williams and W.A.M. Jenkins, Geology of the Amoco-Imp-Skelly A-1 Osprey H-84 well, Grand Banks, Newfoundland, Geol. Surv. Can. Pap. 77-21, 17 pp., 1977.

11 L.F. Jansa, J.P. Bujak and G.L. Williams, Upper Triassic salt deposits of the western North Atlantic, Can. J. Earth Sci. 17, 547-559, 1980.

12 L.F. Jansa and J.A. Wade, Geology of the continental margin off Nova Scotia and Newfoundland, in: Offshore Geology of Eastern Canada, Geol. Surv. Pap. 74-30, 3, 51-105, 1975.

13 H. Schouten and K.D. Klitgord, Mesozoic magnetic anomalies, Western North Atlantic, U.S. Geol. Surv., Misc. Field Stud. Map MF-915, 1977.

14 Y. Bartov, G. Steinitz, M. Eyal and Y. Eyal, Sinistral movement along the Gulf of Aqaba-its age and relation to opening of the Red Sea, Nature 285, 220-221, 1980.

15 H.A. Roeser, A detailed magnetic survey of the southern Red Sea, Geol. Jahrb. 13, 131-153, 1975.

16 J.R. Cochran, A model for the development of the Red Sea, Am. Assoc. Pet. Geol. Bull. 67, 41-69, 1983.

17 C. Mégnien, and F. Mégnien, eds., Synthèse Géologique du Bassin de Paris, I. Stratigraphie et Paléogéographie, Mem. BRGM 101, 468 pp., 1980.

18 M.-F. Brunet and X. Le Pichon, Subsidence of the Paris Basin, J. Geophys. Res. 87, 8547-8560, 1982.

19 M.G. Parsons, A.M. Zagaar and J.J. Curry, Hydrocarbon occurrences in the Sirte Basin, Libya, in: Facts and Principles of World Petroleum Occurrence, A.D. Miall, ed., Can. Soc. Pet. Geol. Mem. 6, 723-732, 1980.
20 H.S. Carslaw and J.C. Jaeger, Heat Conduction in Solids, 510 pp., Oxford University Press, Oxford, 1959.

21 L. Royden and C.E. Keen, Rifting process and thermal evolution of the continental margin of eastern Canada determined from subsidence curves, Earth Planet. Sci. Lett. 51, 343-361, 1980.

22 J.R. Cochran, Simple models of diffuse extension and the pre-seafloor spreading development of the continental margin of the northeastern Gulf of Aden, Oceanol. Acta (Proc. 26th Int. Geol. Congr.), pp. 155-165, 1981.

23 D.S. Sawyer, B.A. Swift, J.G. Sclater and M.N. Toksöz, Extension model for the subsidence of the northern United States Atlantic continental margin, Geology 10, 134-140, 1982.

24 A.B. Watts and M.S. Steckler, Subsidence and eustasy at the continental margin of eastern North America, in: Deep Drilling Results in the Atlantic Ocean: Continental Margins and Paleo-environment, M. Talwani, W. Hey and W.B.F Ryan, pp. 218-234. eds., American Geophysical Union, Washington, D.C., 1979.

25 A.B. Watts, An analysis of isostasy in the world's oceans, 1 Hawaiian-Emperor Seamount Chain, J. Geophys. Res. 83 5989-6004, 1978.

26 D.A. Falvey, The development of continental margins in plate tectonic theory, Aust. Pet. Explor. Assoc. J. 14, 95-106, 1974.

27 J.A. Austin, E. Uchupi, D.R. Shanghnessy and R.D. Ballard, Geology of New England passive margin, Am. Assoc Pet. Geol. Bull. 64, 501-526, 1980.

28 W.P. Dillon, C.K. Paull, R.T. Buffer and J.-P Fail, Structure and development of the southeast Georgia embayment and northern Blake Plateau: preliminary analysis, in: Geological and Geophysical Investigations of Continental Margins, J.S. Watkins, L. Montadert and P.W. Dickerson, eds., pp. 27-42, American Association of Petroleum Geologists, Tulsa, Okla., 1979. 